\title{
əIntraseasonal and Interannual Variability in North American Storm Tracks and Its Relationship to Equatorial Pacific Variability
}

\author{
KEVIN M. GRISE \\ Lamont-Doherty Earth Observatory, Columbia University, Palisades, New York \\ SEOK-WOO SON \\ School of Earth and Environmental Sciences, Seoul National University, Seoul, South Korea \\ JOHN R. GYAKUM \\ Department of Atmospheric and Oceanic Sciences, McGill University, Montreal, Canada
}

(Manuscript received 6 November 2012, in final form 19 March 2013)

\begin{abstract}
Extratropical cyclones play a principal role in wintertime precipitation and severe weather over North America. On average, the greatest number of cyclones track 1) from the lee of the Rocky Mountains eastward across the Great Lakes and 2) over the Gulf Stream along the eastern coastline of North America. However, the cyclone tracks are highly variable within individual winters and between winter seasons. In this study, the authors apply a Lagrangian tracking algorithm to examine variability in extratropical cyclone tracks over North America during winter. A series of methodological criteria is used to isolate cyclone development and decay regions and to account for the elevated topography over western North America. The results confirm the signatures of four climate phenomena in the intraseasonal and interannual variability in North American cyclone tracks: the North Atlantic Oscillation (NAO), the El Niño-Southern Oscillation (ENSO), the Pacific-North American pattern (PNA), and the Madden-Julian oscillation (MJO). Similar signatures are found using Eulerian bandpass-filtered eddy variances. Variability in the number of extratropical cyclones at most locations in North America is linked to fluctuations in Rossby wave trains extending from the central tropical Pacific Ocean. Only over the far northeastern United States and northeastern Canada is cyclone variability strongly linked to the NAO. The results suggest that Pacific sector variability (ENSO, PNA, and MJO) is a key contributor to intraseasonal and interannual variability in the frequency of extratropical cyclones at most locations across North America.
\end{abstract}

\section{Introduction}

Extratropical cyclones are $\sim 1000-\mathrm{km}$-scale baroclinic low pressure systems that strongly contribute to precipitation and severe weather events in midlatitudes, especially during winter. The cyclones chiefly grow via baroclinic instability, as potential energy from horizontal temperature gradients is converted into the rapid

¿Denotes Open Access content.

Corresponding author address: Kevin M. Grise, Lamont-Doherty Earth Observatory, Columbia University, P.O. Box 1000, 61 Route 9W, Palisades, NY 10964-8000.

E-mail: kgrise@ldeo.columbia.edu development and intensification of the cyclones (e.g., Charney 1947; Eady 1949; Hoskins et al. 1985). In the climatology, the preferred regions where extratropical cyclones track are referred to as storm tracks. The location of the storm tracks is largely governed by the locations of the climatological-mean horizontal temperature gradients (e.g., land-ocean boundaries) and the background stationary wave pattern forced by remote orography and diabatic heating (e.g., Chang et al. 2002; Gerber and Vallis 2009; Son et al. 2009).

Over North America, the storm tracks extend eastward from the lee of the Rocky Mountains toward the Great Lakes and parallel the eastern coastline along the Gulf Stream (e.g., Hoskins and Hodges 2002; Eichler and Higgins 2006). Daily behavior of individual extratropical cyclones in the North American storm tracks is 
generally well captured by numerical weather prediction models, but the intraseasonal, interannual, and decadal variability of the cyclones is less understood. Past studies have linked variability in the North American storm tracks to the North Atlantic Oscillation (NAO; Hurrell et al. 2003), the El Niño-Southern Oscillation (ENSO; Eichler and Higgins 2006), the Pacific-North American pattern (PNA; Angel and Isard 1998), and the MaddenJulian oscillation (MJO; Lin et al. 2010; Becker et al. 2011; Zhou et al. 2012). However, the methodology used in these studies varies greatly and makes it challenging to interpret their results quantitatively.

Previous studies have identified storm tracks using four main methods: 1) manual identification (Klein 1957; Zishka and Smith 1980), 2) statistical analysis of bandpass-filtered eddy variances (Blackmon et al. 1977; Trenberth 1991; Chang et al. 2002), 3) analysis of precipitation data (Pfahl and Wernli 2012), and 4) identification using automated Lagrangian algorithms (Murray and Simmonds 1991; Hodges 1994; Sinclair 1997; Ulbrich et al. 2009). Manual identification was common in early research efforts but is unrealistic for modern climatological studies. Bandpass-filtered variances are useful in characterizing the interaction of extratropical weather systems with the general circulation but cannot isolate cyclones from anticyclones or strong from weak systems. Precipitation data are useful in assessing the impacts of extratropical cyclones but are often complicated by localized convection and other mesoscale processes. Lagrangian tracking algorithms automate manual identification techniques but also inherently omit, separate, or join individual cyclone tracks.

The goal of this study is to characterize intraseasonal and interannual variability in the North American storm tracks associated with the NAO, ENSO, PNA, and MJO using a consistent methodology. We apply the Lagrangian tracking algorithm of Hodges (1994, 1995, 1999) and introduce a series of key methodological criteria to analyze only the most salient extratropical cyclones over North America during the winter season. The results qualitatively support previous studies but also provide new linkages between the MJO and the North American storm tracks.

The paper is organized as follows. Section 2 describes the data and methods used in this study. Section 3 documents observed variability in the North American storm tracks associated with the NAO, ENSO, PNA, and MJO. Section 4 compares and contrasts the Lagrangian tracking results with those derived from Eulerian bandpass-filtered eddy variances. Section 5 concludes with a discussion of the results and their relevance for major cities in the United States and Canada.

\section{Data and methods}

\section{a. Data}

The primary data used in this study are geopotential heights, sea level pressure, and winds from the European Centre for Medium-Range Weather Forecasts (ECMWF) Re-Analysis Interim (ERA-Interim; Dee et al. 2011) dataset. The reanalysis data are obtained from ECMWF and begin in 1979. Both pressure and model level data are used. We supplement the reanalysis data with sea surface temperatures from the National Oceanic and Atmospheric Administration (NOAA) Optimal Interpolation version 2 sea surface temperature dataset (Reynolds et al. 2002). The sea surface temperature data are obtained from the Physical Sciences Division of the NOAA/Earth System Research Laboratory and begin in December 1981. For this study, we focus on the 30 years of data included in both datasets: 1982-2011.

\section{b. Indices}

We examine the signatures of four climate phenomena in the North American storm tracks. Temporal variability in the climate phenomena is characterized as follows:

1) NAO variability is characterized using the leading principal component (PC) time series of sea level pressure anomalies over the Atlantic sector $\left(20^{\circ}-\right.$ $80^{\circ} \mathrm{N}, 90^{\circ} \mathrm{W}-40^{\circ} \mathrm{E}$; Hurrell 1995 ). (Virtually identical results are found using a time series of the northern annular mode.)

2) ENSO variability is characterized using the Niño-3.4 index of monthly-mean sea surface temperature anomalies averaged over the central tropical Pacific Ocean $\left(5^{\circ} \mathrm{N}-5^{\circ} \mathrm{S}, 170^{\circ}-120^{\circ} \mathrm{W}\right.$; Barnston et al. 1997 ; Trenberth 1997). The ENSO index is used at lag -1 month, such that the sea surface temperature anomalies lead the storm-track variability by one month.

3) PNA variability is characterized using the definition of Wallace and Gutzler $(1981):{ }^{1 / 4}\left[Z^{*}\left(20^{\circ} \mathrm{N}, 160^{\circ} \mathrm{W}\right)-\right.$ $Z^{*}\left(45^{\circ} \mathrm{N}, 165^{\circ} \mathrm{W}\right)+Z^{*}\left(55^{\circ} \mathrm{N}, 115^{\circ} \mathrm{W}\right)-Z^{*}\left(30^{\circ} \mathrm{N}\right.$, $\left.85^{\circ} \mathrm{W}\right)$ ], where $Z^{*}$ represents standardized $500-\mathrm{hPa}$ geopotential height values at the respective locations (i.e., the geopotential height time series at each location has a mean of zero and a standard deviation of one). Linear regression is used to remove the ENSO index from the PNA index so that the PNA index characterizes variability that is linearly uncorrelated with ENSO.

4) MJO variability is characterized using the paired MJO indices obtained from the Bureau of Meteorology Research Centre of The Centre for Australian Weather and Climate Research [i.e., the so-called real-time multivariate MJO indices (RMM1 and 
RMM2)]. The MJO index time series represent the first two PCs of the combined $15^{\circ} \mathrm{N}-15^{\circ} \mathrm{S}$-averaged 850-hPa zonal wind, 200-hPa zonal wind, and outgoing longwave radiation (OLR) fields with the interannual variability removed (Wheeler and Hendon 2004).

\section{c. Tracking algorithm}

To identify tracks of extratropical cyclones, we use the Lagrangian storm-tracking algorithm developed by Hodges (1994, 1995, 1999). Following Hoskins and Hodges (2002), the algorithm is applied to 6-hourly 850-hPa relative vorticity data that have been filtered to synoptic spatial scales (wavenumbers 5-42). Details of the algorithm are provided in the above references. In brief, the algorithm minimizes a cost function to obtain the smoothest possible set of cyclone tracks that meet a minimum intensity threshold of $1.0 \times 10^{-5} \mathrm{~s}^{-1}$ [ 1 cyclonic vorticity unit $(\mathrm{CVU})]$ over the domain $25^{\circ}-90^{\circ} \mathrm{N}$. The tracks are subject to constraints on smoothness and the maximum displacement of cyclones between time steps. The track database is then filtered for cyclones with a minimum lifetime of 2 days and a minimum track length of $1000 \mathrm{~km}$.

Figure 1 shows the November-March climatology of cyclone tracks, genesis, and lysis as indicated by the Hodges algorithm. The statistics shown in Fig. 1 are comparable to the track density, genesis density, and lysis density defined by Hoskins and Hodges (2002), but here we define the statistics using histograms that assign each cyclone a radius of influence of $500 \mathrm{~km}$ [see also Sinclair (1997)]. In this way, the units in Fig. 1 can be interpreted as the average number of cyclones per month that pass, form, or die within $500 \mathrm{~km}$ of a given grid point.

The results in Fig. 1 qualitatively reproduce those from Fig. 6 of Hoskins and Hodges (2002). In the North American sector, cyclones are most frequent over the central Pacific Ocean, central plains, Great Lakes, and North Atlantic Ocean (Fig. 1, top). Cyclogenesis peaks in the lee of the Rocky Mountains and, to a lesser extent, over regions of large sea surface temperature gradients (Fig. 1, middle). Cyclolysis peaks over coastal Alaska and British Columbia and near Hudson Bay (Fig. 1, bottom).

As in Hoskins and Hodges (2002), the genesis and lysis regions in Fig. 1 are calculated using the first and last points of each cyclone track. However, we found that the first and last points of each cyclone track are highly sensitive to parameter choices of the algorithm and are not necessarily an indication of cyclone development and decay. For these reasons, we use a growth rate metric to determine cyclone development and decay. To do this, we follow Sinclair (1997) and apply the following criteria: 1) all cyclones must have at least peak intensity of $3 \mathrm{CVU}$,
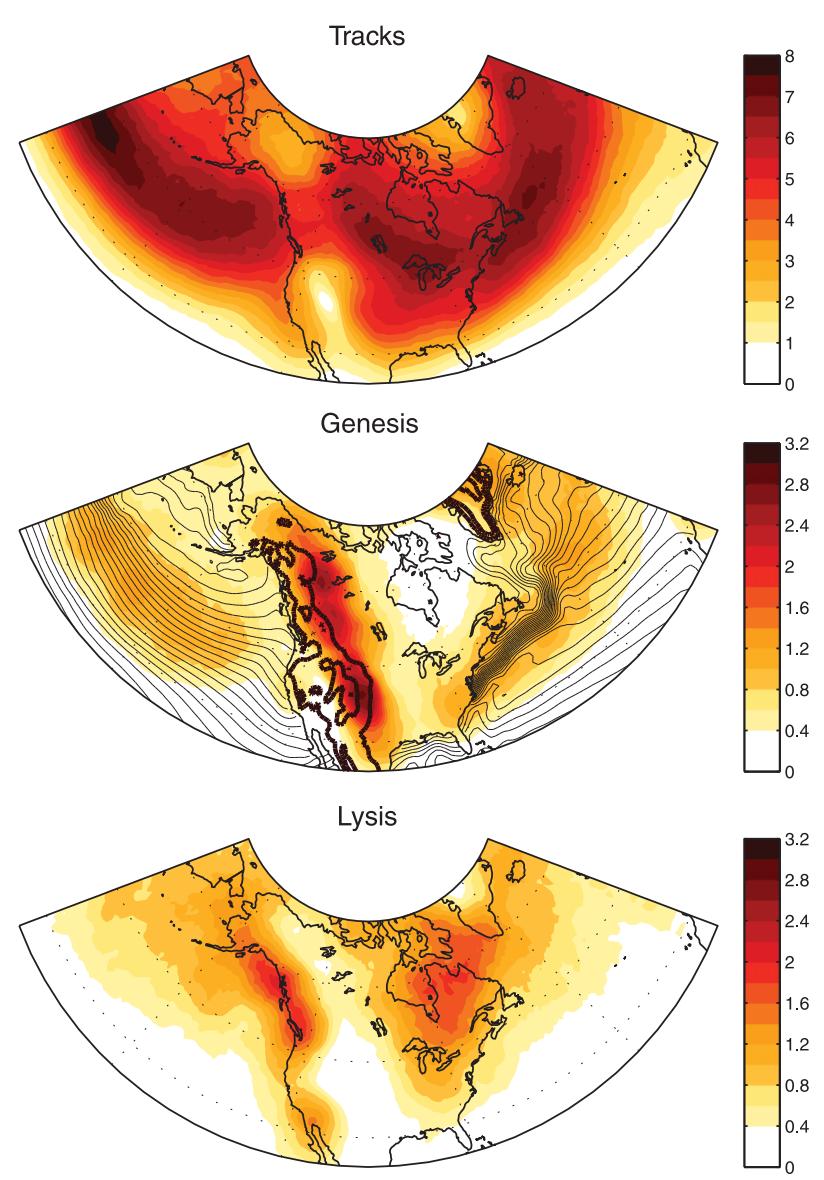

FIG. 1. 1982-2011 November-March climatology of North American storm tracks. Storm tracks are defined using the ERA-Interim $850-\mathrm{hPa}$ relative vorticity field and the Hodges (1994) algorithm. Individual tracks are assigned to a 500-km radius region surrounding the vorticity maximum. (top) Average number of cyclones per month. (middle) Average number of genesis events (i.e., initial track points) per month. (bottom) Average number of lysis events (i.e., final track points) per month. The shading interval is (top) 0.5 cyclones month ${ }^{-1}$ and (middle),(bottom) 0.2 cyclones month ${ }^{-1}$. The middle panel also displays contours of elevation (thick lines; contour interval: $1000 \mathrm{~m}$ ) and sea surface temperature (thin lines; contour interval: $1 \mathrm{~K}$ ).

2) developing cyclones must have a growth rate exceeding $2 \mathrm{CVU} \mathrm{day}^{-1}$, and 3 ) decaying cyclones must have a decay rate exceeding $2 \mathrm{CVU}$ day $^{-1}$.

The left column of Fig. 2 reproduces the results from Fig. 1, but using the modified statistics discussed above. The pattern of cyclone tracks in Fig. 2 is virtually identical to the results in Fig. 1, but the cyclone development and decay regions in Fig. 2 differ substantially from the genesis and lysis regions in Fig. 1. First, because cyclones can undergo rapid growth or decay at multiple locations, the magnitudes in the middle and bottom panels of Fig. 2 are larger than those in Fig. 1. Second, the development regions in Fig. 2 (middle left) have comparable amplitude 

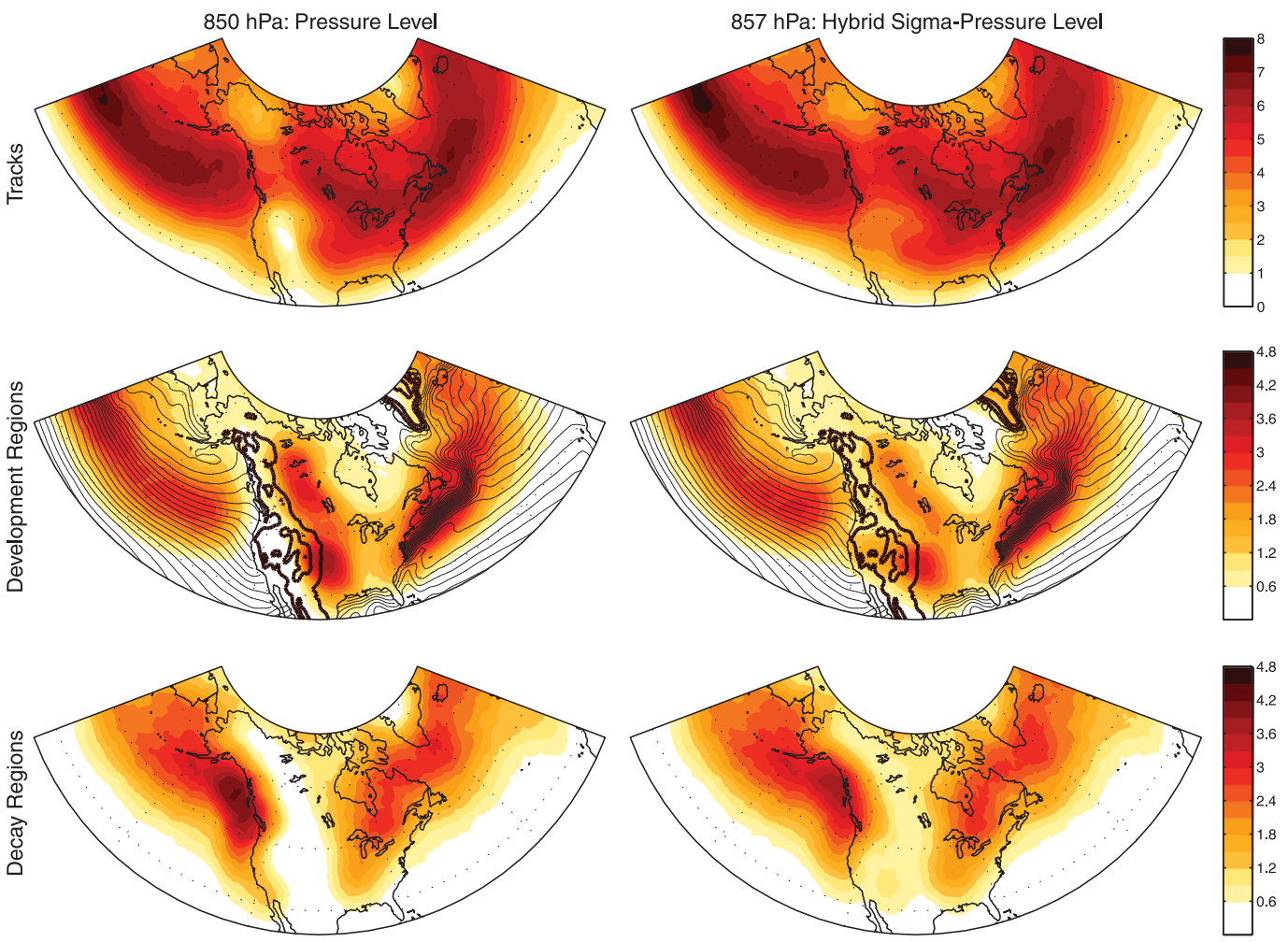

FIG. 2. (left) As in Fig. 1, but only for cyclones with maximum intensity greater than $3.0 \times 10^{-5} \mathrm{~s}^{-1}$. Genesis and lysis are defined using cyclone development and decay regions. Development regions are defined as all locations where a cyclone's growth rate exceeds $2.0 \times 10^{-5} \mathrm{~s}^{-1} \mathrm{day}^{-1}$, and decay regions are defined as all locations where a cyclone's decay rate exceeds $2.0 \times 10^{-5} \mathrm{~s}^{-1}$ day $^{-1}$. The shading interval is (top) 0.5 cyclones month ${ }^{-1}$ and (middle),(bottom) 0.3 cyclones month $^{-1}$. (right) As in (left), but for cyclone tracking performed on the ERAInterim hybrid sigma-pressure level nearest to $850 \mathrm{hPa}$.

in the lee of the Rockies, over the central Pacific Ocean, and over the Gulf Stream. Third, the development regions in Fig. 2 (middle left) are highly localized over the maximum sea surface temperature gradient along the east coast of North America, indicating that the modified statistics effectively capture baroclinic cyclone development along the Gulf Stream. Fourth, the decay regions in Fig. 2 (bottom left) are widely spread from the North Pacific Ocean to the west coast of North America and from northeastern Canada to the Greenland Sea. Finally, the development regions in the lee of the Rocky Mountains in Fig. 2 (middle left) are shifted slightly eastward with fewer storms developing over high terrain than in Fig. 1 (middle), and the decay regions along the west coast of North America are centered over the Pacific Ocean in Fig. 2 (bottom left) as opposed to over coastal regions in Fig. 1 (bottom). Thus, the genesis and lysis patterns in Fig. 1 more strongly reflect locations where the $850-\mathrm{hPa}$ flow intersects topography (bold lines in Fig. 1, middle) than actual cyclone development and decay regions.
To improve the storm-track signatures over western North America, we have also run the Hodges algorithm using 6-hourly relative vorticity data on the ERA-Interim model level closest to $850 \mathrm{hPa}$. Synoptic-scale storms are commonly observed over elevated regions of western North America (e.g., Lareau and Horel 2012) but are inherently omitted in analyses of pressure levels (e.g., $850 \mathrm{hPa}$ ) that intersect the ground. The model level analysis is based on a hybrid sigma-pressure vertical coordinate system, which smoothly transitions from a full sigma vertical coordinate at the surface to a full pressure vertical coordinate in the upper atmosphere. Thus, in the lower atmosphere, the model level behaves as a sigma level and alleviates the intersection of the flow with topography.

The results from the model level analysis are shown in the right column of Fig. 2. By definition, the results are virtually identical to those in Fig. 2 (left column) over regions without elevated topography. However, the model level analysis permits cyclones to track over the Rocky Mountains and thus mitigates several artificial 
TABLE 1. November-March composites of the climate indices defined in section $2 b$ for the conditions listed in the left column. MJO amplitude is defined as $\left[(\mathrm{RMM} 1)^{2}+(\mathrm{RMM} 2)^{2}\right]^{1 / 2}$, and the MJO phases are defined as in Wheeler and Hendon (2004). All units are in standard deviations. Values by construction are set boldface, and values that are $95 \%$ significant via a Monte Carlo test are set italic.

\begin{tabular}{lrrrc}
\hline \hline & NAO & ENSO & PNA & MJO (phase) \\
\hline NAO $>1$ & $\mathbf{1 . 4 7}$ & -0.03 & -0.23 & $0.18(4)$ \\
NAO $<-1$ & $-\mathbf{1 . 5 6}$ & -0.01 & 0.23 & $0.25(8)$ \\
ENSO $>1$ & -0.09 & $\mathbf{1 . 5 3}$ & 0.24 & $0.03(4)$ \\
ENSO $<-1$ & 0.08 & $-\mathbf{1 . 3 2}$ & 0.03 & $0.11(7)$ \\
PNA $>1$ & -0.28 & -0.07 & $\mathbf{1 . 4 4}$ & $0.39(8)$ \\
PNA $<-1$ & 0.21 & 0.01 & $-\mathbf{1 . 5 3}$ & $0.35(5)$ \\
MJO $>1$ (phase 3) & -0.04 & -0.02 & -0.09 & $\mathbf{1 . 6 6 ( 3 )}$ \\
MJO $>1$ (phase 4) & 0.26 & 0.13 & -0.27 & $\mathbf{1 . 7 1 ( 4 )}$ \\
MJO $>1$ (phase 5) & 0.2 & 0.07 & -0.25 & $\mathbf{1 . 6 6}(5)$ \\
MJO $>1$ (phase 6) & 0.02 & 0.01 & -0.39 & $\mathbf{1 . 6 3 ( 6 )}$ \\
\hline
\end{tabular}

features in the storm-track statistics: 1) the void in cyclone tracks over the southwestern United States (Fig. 2, top) and 2) the bias in cyclone development in the lee of the Rocky Mountains caused by the intersection of the 850-hPa pressure level with topography (Fig. 2, middle). As such, we choose to use the model level results throughout the remainder of this study.

\section{Intraseasonal and interannual variability in North American storm tracks}

In this section, we examine the variability in the North American storm tracks associated with the four climate phenomena outlined in section $2 \mathrm{~b}$ : the NAO, ENSO, PNA, and MJO. To do this, we calculate pentad-mean storm-track statistics (following the methodology used in the right column of Fig. 2), remove the mean seasonal cycle by subtracting the long-term mean for each pentad, and composite the anomalies for periods when the climate indices exceed one standard deviation in amplitude. Statistical significance of the composites is assessed using a Monte Carlo test with 1000 random samples of events of equal number and duration to those in the climate record.

Table 1 lists composite values of the climate indices during the periods considered in this section. For each condition listed in the left column of Table 1, the associated climate index is constrained to exceed one standard deviation in amplitude. Composites of the other indices are small but reveal a statistically significant overlap among the NAO, PNA, and selected phases of the MJO. Similar relationships among the NAO, PNA, and $\mathrm{MJO}$ are also reflected in correlations between the indices (Table 2) and in the cluster analysis of Riddle et al. (2013). The overlap in the indices is not unexpected
TABLE 2. November-March correlations of the climate indices defined in section $2 \mathrm{~b}$. By construction, the ENSO and PNA indices are uncorrelated, and the two MJO indices are orthogonal to one another (see section 2 b). Values that are $95 \%$ significant are set italic.

\begin{tabular}{lccrr}
\hline \hline & MJO (RMM2) & MJO (RMM1) & PNA & ENSO \\
\hline NAO & -0.04 & 0.14 & -0.14 & -0.01 \\
ENSO & -0.05 & 0.00 & 0.00 & \\
PNA & -0.05 & -0.21 & & \\
MJO (RMM1) & 0.00 & & & \\
\hline
\end{tabular}

because 1) Rossby wave trains excited by tropical convection in the Pacific Ocean project strongly onto the PNA (e.g., Horel and Wallace 1981) and 2) the propagation of Rossby wave trains into the Atlantic sector may modulate the phase of the NAO (Cassou 2008; Lin et al. 2009). To first order, we will assume that the composites shown below are independent of one another, but we will address any significant overlap in the indices that is reflected in the results.

The composites discussed below primarily result from variability in the climate indices on weekly time scales. Apart from ENSO (which is well known to vary on seasonal time scales), the composites for the NAO, PNA, and selected phases of the MJO comprise events of average 5-10-day duration (Table 3, middle column). The time scales of the events agree well with the $e$-folding time scales of the NAO and PNA (Feldstein 2000) and with the average propagation speed of the MJO (Wheeler and Hendon 2004). The sample sizes for the composites are relatively equal for the NAO, ENSO, and PNA but are substantially less for the phases of the MJO (Table 3, right column). Although there are fewer degrees of freedom, qualitatively similar composites for the NAO, ENSO, and PNA can also be derived using monthlymean data (not shown).

TABLE 3. Characteristics of the events comprising the composites listed in Table 1.

\begin{tabular}{lcc}
\hline \hline & $\begin{array}{c}\text { Avg event } \\
\text { length (days) }\end{array}$ & $\begin{array}{c}\text { No. (percentage) of } \\
\text { wintertime pentads } \\
\text { encompassed by all events }\end{array}$ \\
\hline NAO $>1$ & 10 & $142(16 \%)$ \\
NAO $<-1$ & 11 & $152(17 \%)$ \\
ENSO $>1$ & 93 & $168(19 \%)$ \\
ENSO $<-1$ & 120 & $168(19 \%)$ \\
PNA $>1$ & 8 & $147(16 \%)$ \\
PNA $<-1$ & 10 & $161(18 \%)$ \\
MJO $>1$ (phase 3) & 7 & $59(7 \%)$ \\
MJO $>1$ (phase 4) & 6 & $52(6 \%)$ \\
MJO $>1$ (phase 5) & 6 & $50(6 \%)$ \\
MJO $>1$ (phase 6) & 6 & $53(6 \%)$ \\
\hline
\end{tabular}



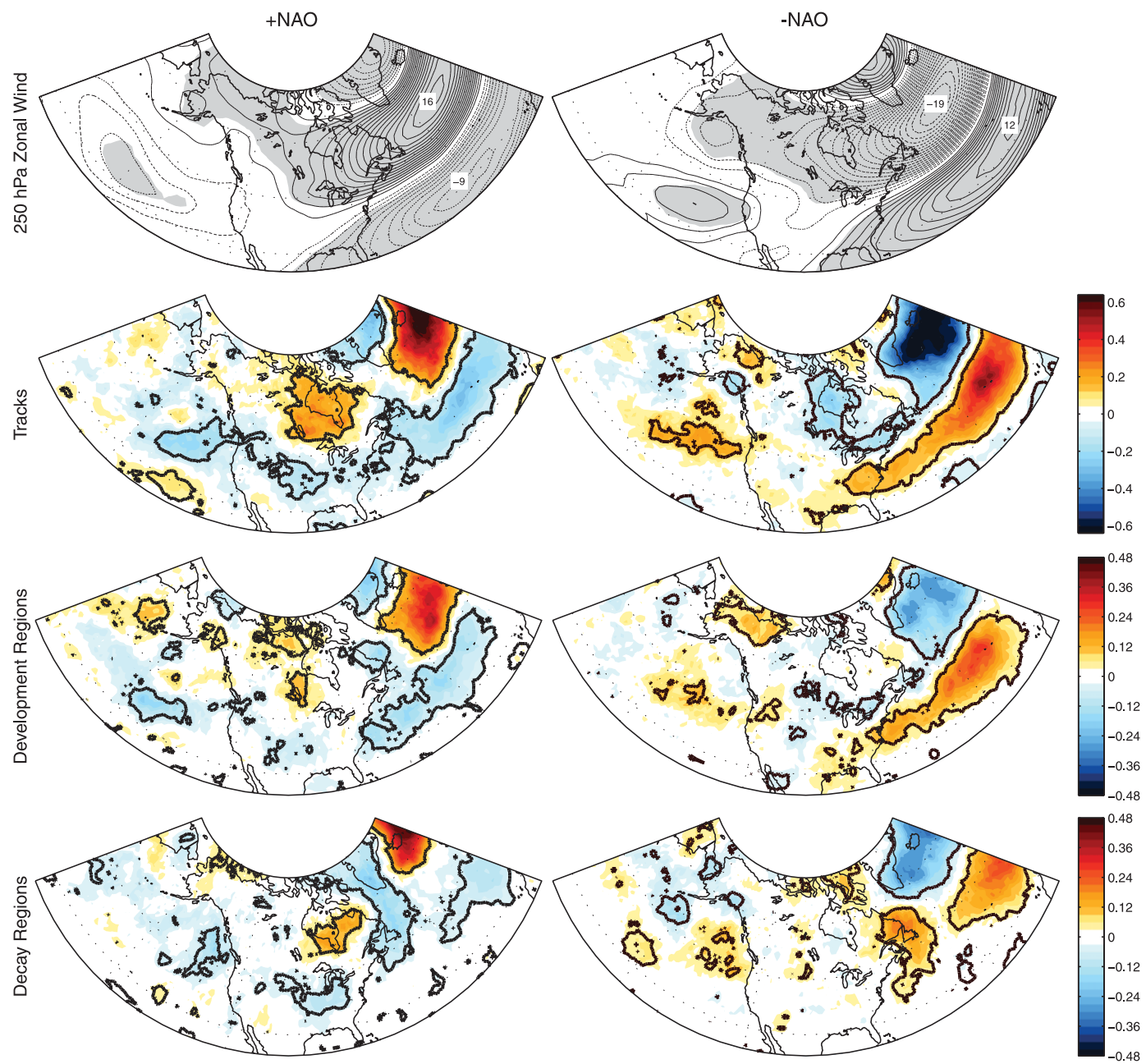

FIG. 3. Composites of zonal wind and storm-track anomalies associated with the phases of the NAO during November-March. The composites are taken over (from top to bottom) 250-hPa zonal wind, all cyclone tracks, tracks of developing cyclones, and tracks of decaying cyclones, respectively, for (left) NAO $>+1$ standard deviation and (right) NAO $<-1$ standard deviation. The contour interval is (from top to bottom) $1 \mathrm{~m} \mathrm{~s}^{-1}, 0.04$ cyclones pentad $^{-1}$, 0.03 cyclones pentad $^{-1}$, and 0.03 cyclones pentad $^{-1}$, respectively. Regions that are $95 \%$ significant via a Monte Carlo test are denoted by (top row) gray shading and (bottom three rows) thick bolded outlines.

\section{a. NAO}

The composites for the NAO are shown in Fig. 3. The top row of Fig. 3 shows the composites of 250-hPa zonal wind anomalies, and the bottom three rows of Fig. 3 show composites of the storm-track anomalies: cyclone tracks (second row), cyclone development regions (third row), and cyclone decay regions (bottom row). Recall that the term anomalies here refers to deviations about the mean seasonal cycle.

The NAO is characterized by a meridional shift in atmospheric mass between the Icelandic low and Azores high and consequently by a meridional shift in the zonal wind maximum over the North Atlantic Ocean (e.g., Hurrell et al. 2003; Fig. 3, top row). In the canonical view of the NAO, the zonal wind anomalies are confined to the North Atlantic sector. However, Fig. 3 shows significant zonal wind anomalies not only over the North Atlantic Ocean and eastern North America but also over the North Pacific Ocean. The Pacific signatures largely reflect the nonnegligible co-occurrence of NAO events with PNA and MJO events (Table 1).

Comparison of the 250-hPa zonal wind anomalies and storm-track anomalies associated with the NAO reveals that the storm-track shift closely mirrors the shift in the zonal wind, with enhanced cyclone tracks in regions of anomalous cyclonic shear and suppressed cyclone tracks in regions of anomalous anticyclonic shear (Fig. 3, second row). The absence of storm track change in the region near the Labrador Sea [see also Fig. 6 of Hodges 
(2008)] reflects sizeable shear in the 250-hPa meridional wind (not shown) of opposite sign to that in the zonal wind (Fig. 3, top row). Thus, the storm tracks are strongly anchored to the upper-tropospheric flow on intraseasonal and interannual time scales (Lau 1988; Athanasiadis et al. 2010).

The storm-track shift documented here corresponds well with previous results (e.g., Rogers 1990; Hurrell et al. 2003; Hodges 2008). During the positive phase of the NAO, the storm track is shifted poleward over the Atlantic Ocean, and there are enhanced cyclone tracks over central Canada near Hudson Bay (Wang et al. 2006) and in the vicinity of the Icelandic low (Serreze et al. 1997). As anticipated from the regional nature of the NAO, no significant response is observed over western North America. During the negative phase of the NAO, the storm track is shifted equatorward over the Atlantic Ocean, and there are enhanced cyclone tracks extending eastward from Cape Hatteras. In general, regions of anomalous cyclone development are located upstream of or collocated with the enhanced cyclone tracks (Fig. 3, third row), and regions of anomalous cyclone decay are located downstream of the enhanced cyclone tracks (Fig. 3, bottom row). The negative phase of the NAO is also marked by enhanced cyclone decay near Newfoundland (Fig. 3, bottom right), as systems tracking along the east coast of North America preferentially decay in this region. Overall, the anomalies associated with the NAO are roughly linear between phases.

To be clear, the NAO is a teleconnection pattern defined by meridional shifts in the winds and storm tracks over the North Atlantic sector. That is, the same high-frequency midlatitude transient eddies that are manifested in the storm-track signatures in Fig. 3 are also thought to drive the NAO (e.g., Thompson et al. 2003) and its persistence (e.g., Lorenz and Hartmann 2003; Barnes and Hartmann 2010). Thus, in some sense, the signatures in Fig. 3 are not linked to the NAO; they are the NAO.

\section{b. ENSO}

The composites for ENSO are shown in Fig. 4. The positive phase of ENSO (i.e., El Niño) is characterized by anomalously warm sea surface temperatures and enhanced convection over the central-eastern tropical Pacific Ocean. The resultant changes in tropical diabatic heating strengthen the Hadley circulation and enhance the subtropical jet over the eastern Pacific and Atlantic Oceans (e.g., Bjerknes 1969; Fig. 4, top left). The changes in tropical heating also modify the Rossby wave train excited from low latitudes (Hoskins and Karoly 1981; Sardeshmukh and Hoskins 1988). Thus, the zonal wind and storm-track anomalies associated with ENSO reflect the nonlinear interaction among tropical diabatic heating, the Rossby wave train, and midlatitude transient eddies (Held et al. 1989). As is the case for the NAO, the storm-track anomalies associated with ENSO (Fig. 4, second row) closely mirror the 250-hPa zonal wind anomalies (Fig. 4, first row), particularly during El Niño (left column).

During El Niño, the Pacific storm track is shifted eastward and equatorward (Trenberth and Hurrell 1994; Straus and Shukla 1997; Zhang and Held 1999), so there are enhanced cyclone tracks, development, and decay over the central Pacific Ocean (Fig. 4, left column; see also Eichler and Higgins 2006). El Niño is also associated with enhanced cyclone tracks and development over the Gulf of Mexico and southeastern United States and reduced cyclone tracks and development over the Great Lakes and northern plains (Noel and Changnon 1998; Hirsch et al. 2001; Eichler and Higgins 2006). During La Niña, the storm-track changes are weaker and less robust (Fig. 4, right column). Modest increases in cyclone tracks and development are observed over the Pacific Northwest, northern plains, and Great Lakes. The polarity and spatial structure of the La Niña response is consistent with previous studies, but the robustness and magnitude of the results is highly variable among studies (Noel and Changnon 1998; Hirsch et al. 2001; Eichler and Higgins 2006).

\section{c. PNA}

The composites for the PNA are shown in Fig. 5. The PNA is characterized by the fluctuation in amplitude of the climatological-mean stationary wave pattern (i.e., a trough over the central-eastern North Pacific Ocean, a ridge over western North America, and a trough over eastern North America; Wallace and Gutzler 1981). Because the PNA is influenced by external forcing (i.e., Rossby wave trains excited from tropical diabatic heat sources; Horel and Wallace 1981), we have removed the component of the PNA index that is linearly correlated with ENSO to avoid resampling variability shown in Fig. 4. The 250-hPa zonal wind anomalies and storm-track anomalies in Fig. 5 reflect the enhanced (suppressed) stationary wave pattern during the positive (negative) phase of the PNA. Statistically significant anomalies are also evident over the North Atlantic Ocean. The Atlantic signatures resemble those associated with the NAO (Fig. 3) and are linked to the nonnegligible overlap among PNA, NAO, and MJO indices (Table 1).

Once again, the storm-track anomalies associated with the PNA (Fig. 5, second row) closely mirror the zonal wind anomalies (Fig. 5, first row). The storm-track anomalies also resemble those associated with ENSO in midlatitudes. The resemblance is particularly strong for 

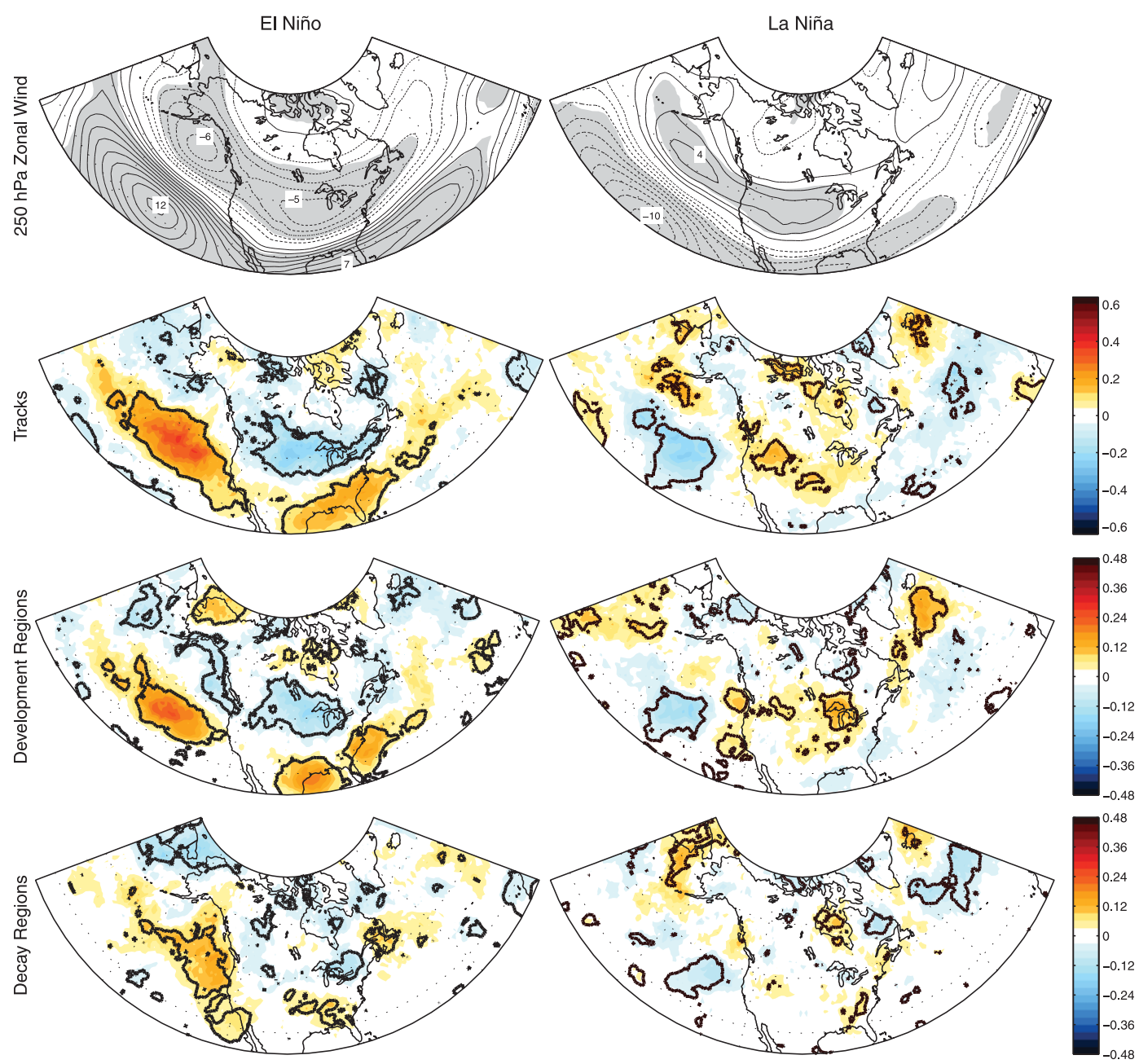

FIG. 4. As in Fig. 3, but for the phases of ENSO.

the anomalies associated with El Niño and the positive phase of the PNA (Figs. 4 and 5, left column). The resemblance reflects the fact that the teleconnection pattern driven by extratropical internal dynamics over the North Pacific-North American sector (Nakamura et al. 1987) is similar to that driven by ENSO-like tropical forcing (top left of Figs. 4 and 5; see also significant co-occurrence of PNA with ENSO in Table 1) ${ }^{1}$. As is the case for the NAO, the PNA is largely driven and maintained by high-frequency midlatitude transient

\footnotetext{
${ }^{1}$ In Table 1, the significant occurrence of the positive phase of the PNA during El Niño events reflects nonlinearity in the ENSOPNA relationship. Although the ENSO index has been linearly removed from the PNA index (see section $2 b$ ), there remains a preference for the positive phase of the PNA to occur during large amplitude El Niño events. However, there is no longer a significant preference for a given phase of the ENSO cycle to occur during large-amplitude PNA episodes.
}

eddies, so the storm-track signatures in Fig. 5 define the PNA pattern.

During the positive phase of the PNA, the Pacific storm track is shifted equatorward and truncates near the western edge of the ridge over western North America (Lau 1988), and there are enhanced cyclone tracks, development, and decay over the central Pacific Ocean (Fig. 5, left column). During the negative phase of the PNA, the enhanced cyclone tracks, development, and decay shift northeastward toward the $\mathrm{Pa}$ cific Northwest (Fig. 5, right column). Over eastern North America, the positive phase of the PNA is associated with enhanced cyclone tracks and development over the southeastern United States, and the negative phase of the PNA is associated with enhanced cyclone tracks and development over the Great Lakes (Leathers et al. 1991; Angel and Isard 1998). The anomalies associated with the PNA are roughly linear between phases. 

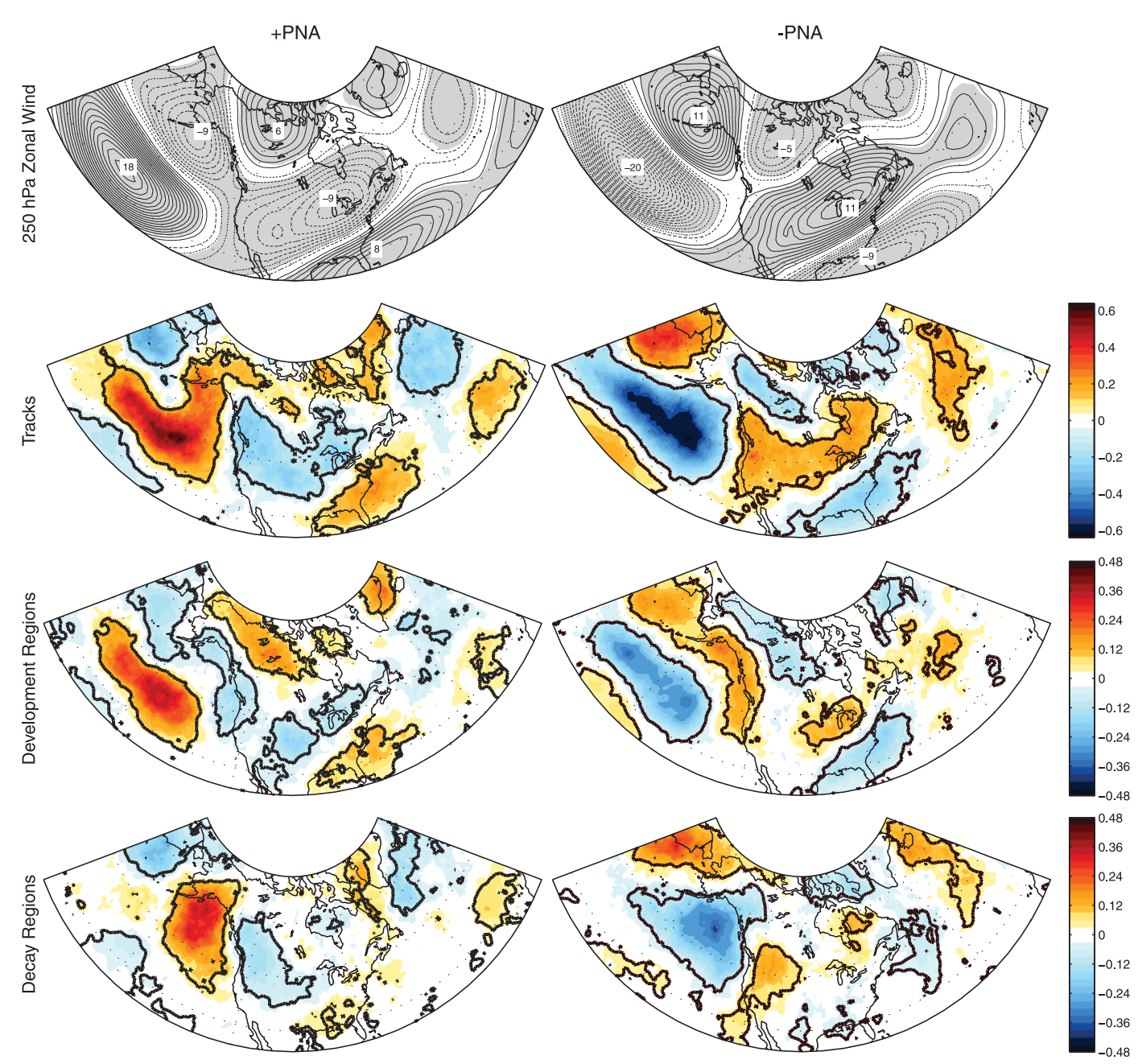

FIG. 5. As in Fig. 3, but for the phases of the PNA pattern.

\section{d. $M J O$}

The composites for the MJO are shown in Fig. 6. The MJO is characterized by a 40-50-day oscillation in periods of anomalous tropical convection that propagate eastward from the Indian Ocean into the central Pacific Ocean (e.g., Madden and Julian 1994). The MJO events in the composites in Fig. 6 are selected using the criteria of L'Heureux and Higgins (2008): (i) the amplitude $\left[(\mathrm{RMM} 1)^{2}+(\mathrm{RMM} 2)^{2}\right]^{1 / 2}$ must be greater than one standard deviation for the duration of the event, (ii) the phases must be in numerical order (i.e., the MJO convection must propagate eastward in time), (iii) the event must continue for at least 30 days, and (iv) the event cannot remain in a given phase (i.e., stationary) for more than 20 days. We display results for MJO phases 3-6, which represent the period during which enhanced tropical convection propagates eastward from the Indian Ocean into the western Pacific Ocean. We focus on these phases because they are linked to the most robust storm-track response over North America.

The top row of Fig. 6 shows the 250-hPa zonal wind anomalies associated with MJO phases 3-6. As the MJO convection moves from the Indian Ocean into the western Pacific Ocean, a meridional couplet of westerly and easterly wind anomalies propagates from the central Pacific Ocean over North America. As is the case for ENSO, the wind anomalies reflect changes in tropical diabatic heating, the associated Rossby wave train, and nonlinear interactions between midlatitude transient eddies and the background flow (Deng and Jiang 2011). The storm-track anomalies associated with the MJO are varied but generally mirror the zonal wind anomalies (Fig. 6, second row).

To our knowledge, Fig. 6 represents the first attempt to quantify MJO storm-track anomalies using a Lagrangian storm-tracking algorithm. The results are consistent with several recent studies that have explored linkages 

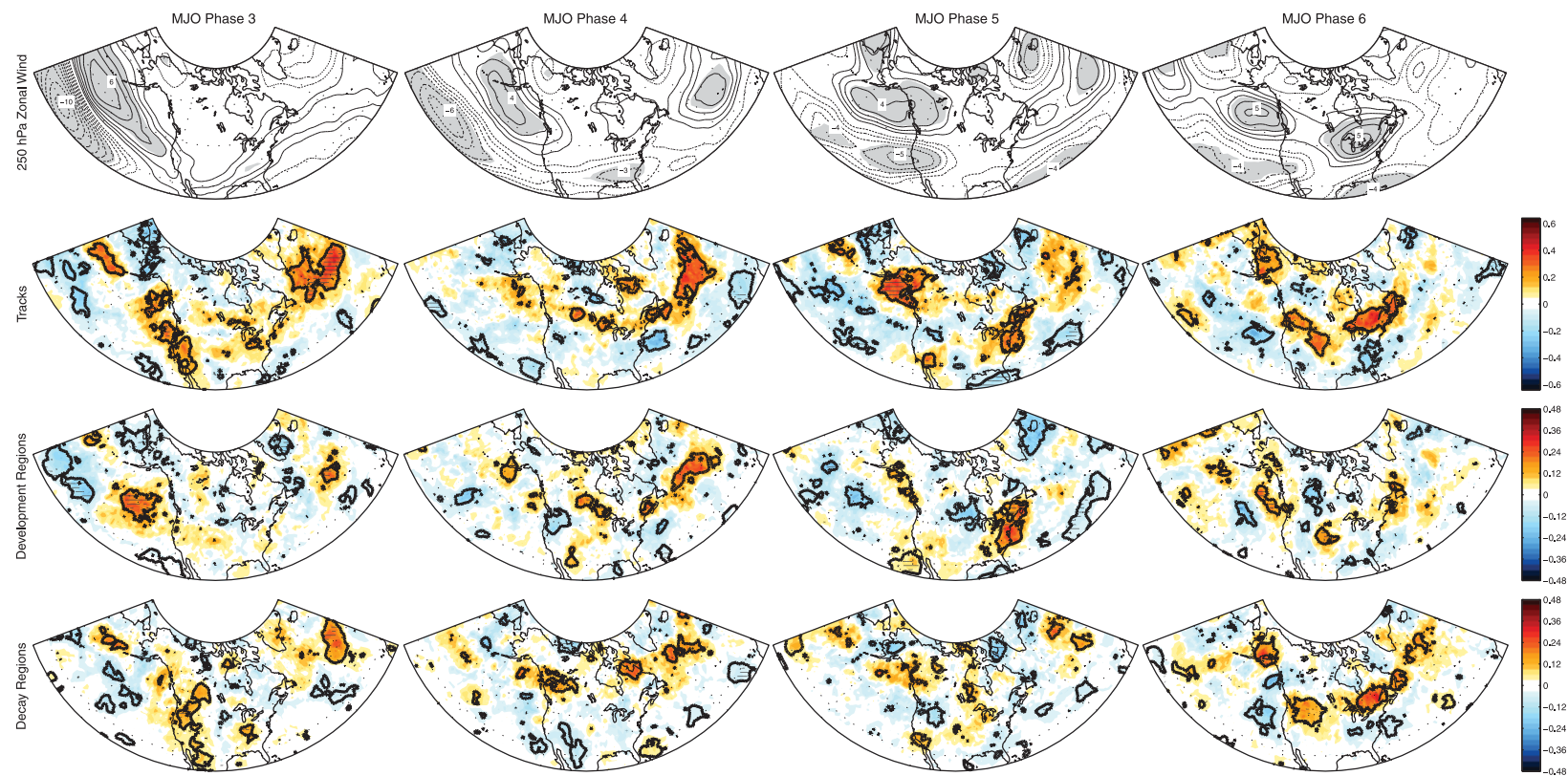

FIG. 6. As in Fig. 3, but for selected phases of the MJO. Phases are defined as in Wheeler and Hendon (2004). The hatching in the bottom three rows indicates regions that are statistically significant using both the RMM MJO indices (Wheeler and Hendon 2004) and the OLRonly based MJO indices defined in Straub (2013). The OLR-only indices are defined in a similar manner to the RMM indices, but using only the first two empirical orthogonal functions of the $15^{\circ} \mathrm{N}-15^{\circ} \mathrm{S}$-averaged OLR field.

between the MJO and precipitation over North America (Lin et al. 2010; Becker et al. 2011; Zhou et al. 2012), but provide a more conclusive linkage between those observations and the entire storm-track response over the North American continent. When the MJO convection is over the Indian Ocean (i.e., phase 3), enhanced cyclone tracks, development, and decay are observed along the Pacific coast of North America (Fig. 6, left column). By phase 4 , the storm-track anomalies are most apparent across western and central Canada (Fig. 6, second column; see also Lin et al. 2010). Phases 3 and 4 of the MJO are also associated with robust storm-track signatures over the North Atlantic Ocean, which reflect the linkage of the MJO with the positive phase of the NAO during these phases (Cassou 2008; Lin et al. 2009; see also Table 1).

As the MJO convection propagates into the western Pacific Ocean, the most robust storm-track anomalies over North America shift eastward: phases 5-6 of the MJO are marked by enhanced cyclone tracks and development over the Great Lakes region and reduced cyclone tracks and development over the southeastern United States (Fig. 6, right two columns). Thus, the zonal wind and storm-track anomalies associated with MJO phases 5-6 resemble those associated with the negative phase of the PNA (Fig. 5, right column; see also Table 1 and Riddle et al. 2013). However, the anomalies associated with the MJO are less organized, shifted slightly northeastward over eastern North America, and do not indicate dramatic storm track changes over the North Pacific Ocean.

Of the four climate phenomena considered in this section, the MJO is associated with the least robust storm-track anomalies. This is presumably because of the limited sampling and relatively short time scale of each MJO phase (Table 3). Consequently, while the overall pattern of storm-track anomalies in Fig. 6 appears to be reproducible, the magnitude and statistical significance of individual features are dependent on the selection criteria used for the MJO events. Certain facets of the MJO may be better described by OLR-based MJO indices rather than the RMM indices used here (see discussion in Straub 2013). The hatching in Fig. 6 indicates the storm-track anomalies in which the reader should have the most confidence: those that are statistically significant using both the RMM indices and OLR-based MJO indices.

\section{Comparison with Eulerian bandpass-filtered eddy statistics}

In this section, we compare the storm-track signatures derived from the Lagrangian tracking algorithm (as shown in section 3) with those derived from Eulerian bandpass-filtered eddy statistics. To do this, we calculate the 850-hPa eddy kinetic energy associated with 2-6-day bandpass-filtered eddies: 


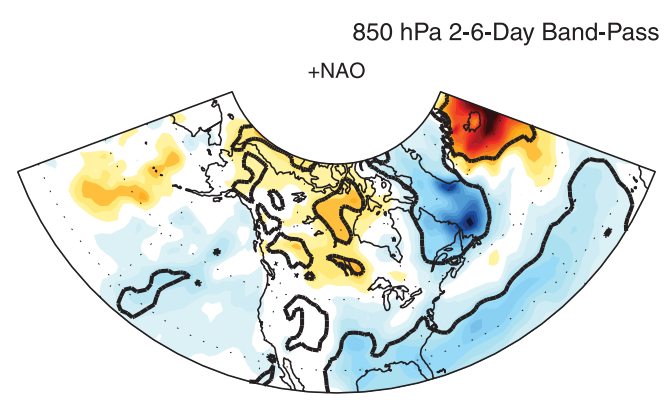

850 hPa 2-6-Day Band-Pass Filtered Eddy Kinetic Energy
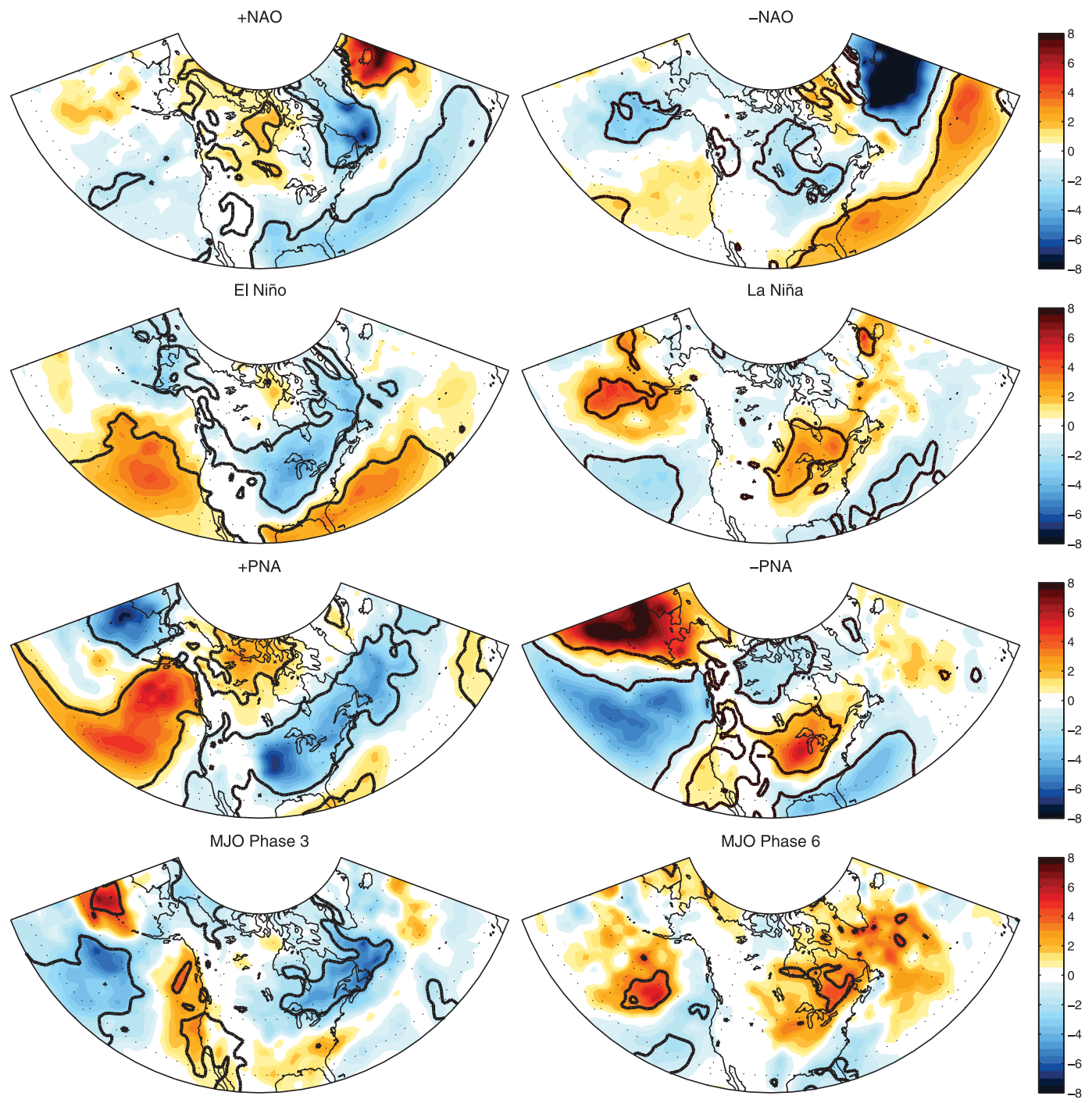

FIG. 7. Composites of the 850-hPa 2-6-day bandpass-filtered eddy kinetic energy anomalies associated with selected phases of (from top to bottom) the NAO, ENSO, the PNA, and the MJO during November-March. The composites are taken over periods during which the corresponding indices exceed one standard deviation in amplitude. The contour interval is $0.5 \mathrm{~m}^{2} \mathrm{~s}^{-2}$. Regions that are $95 \%$ significant via a Monte Carlo test are denoted by thick bolded outlines.

$$
\frac{1}{2}\left(u^{2}+v^{2}\right)
$$

In (1), $u$ is the $850-\mathrm{hPa}$ zonal wind, $v$ is the $850-\mathrm{hPa}$ meridional wind, and the primes represent 2-6-day bandpass-filtered data.

Figure 7 shows composites of the eddy kinetic energy anomalies associated with the NAO, ENSO, PNA, and two selected phases of the MJO. The composites are constructed in an identical manner to those shown in Figs. 3-6. Overall, the eddy kinetic energy anomalies in Fig. 7 strongly resemble the cyclone track anomalies derived from the Lagrangian algorithm (Figs. 3-6, second row). Recall, however, that the eddy kinetic energy composites encompass anticyclonic and cyclonic systems of all intensities, whereas the composites from the Lagrangian tracking algorithm isolate the stronger cyclonic systems. As a result, the eddy kinetic energy composites sample a greater number of systems than those shown in Figs. 3-6.

The most notable difference between the eddy kinetic energy composites and the Lagrangian cyclone track composites is the meridional position of the anomalies. As documented in previous studies, the eddy kinetic 
energy anomalies closely follow the anomalies in the zonal wind field (Figs. 3-6, top row), with enhanced eddy activity in regions of westerly wind anomalies (Lau 1988; Chang et al. 2002; Athanasiadis et al. 2010). Because the Lagrangian cyclone track anomalies include only cyclonic systems, the track anomalies are on average shifted poleward of the eddy kinetic energy anomalies (i.e., to the cyclonic side of the background-mean westerly flow) (see also Wallace et al. 1988). The poleward shift is most apparent at midlatitudes, where the background westerly flow is largest.

Other differences between the eddy kinetic energy composites and Lagrangian cyclone track composites are apparent during the positive phase of the NAO and phase 3 of the MJO. In both cases, the eddy kinetic energy composites indicate significant negative anomalies over northeastern North America and the Labrador Sea (Fig. 7, top and bottom left), whereas the Lagrangian cyclone track composites indicate weak or oppositely signed anomalies over this region (left panel of second row in Figs. 3 and 6). The reasons behind these differences are unclear, but presumably lie in anticyclonic systems or in cyclonic systems excluded from the Lagrangian tracking algorithm.

\section{Discussion}

In this study, we confirmed the unique signatures of the NAO, ENSO, PNA, and MJO in the intraseasonal and interannual variability in the North American storm tracks during the winter season. The signatures were derived using a modified set of Lagrangian storm-track statistics that isolates cyclone development and decay regions and accounts for the presence of elevated terrain over western North America. Qualitatively similar signatures were also derived using Eulerian bandpassfiltered eddy variances.

Several key observations have resulted:

1) Storm-track variability is closely anchored to variability in the upper-tropospheric winds. Previous studies have emphasized a strong linkage between westerly wind anomalies and positive anomalies in bandpass-filtered eddy variance metrics of the storm tracks (Lau 1988; Athanasiadis et al. 2010). Because actual cyclone tracks are similar in structure but shifted slightly poleward from the bandpass-filtered statistics, the enhancement in cyclone tracks occurs on the poleward side of the westerly wind anomaly where anomalous cyclonic wind shear occurs.

2) Storm-track variability associated with ENSO and MJO phases 5-6 has qualitatively similar character to that associated with the PNA over eastern North
America: a dipole in southwest-northeast-oriented cyclone tracks between the southeastern United States and the Great Lakes region. This is likely due to the fact that the three climate phenomena are all associated with similar Rossby wave trains that extend from the central tropical Pacific Ocean over North America (Fig. 8).

3) Storm-track variability associated with the NAO, ENSO, PNA, and MJO is relevant for locations throughout central-eastern North America. Each climate phenomenon is associated with a distinct meridional shift in cyclone tracks over these regions.

In practice, what is the relative importance of the NAO, ENSO, PNA, and MJO storm-track signatures for the cyclone tracks at individual locations throughout central-eastern North America? To explore this question, we construct time series of cyclone counts at four cities in the eastern United States and Canada: Atlanta, Georgia; New York, New York; Toronto, Ontario, Canada; and St. John's, Newfoundland, Canada.

The left column of Fig. 9 shows point correlations between the cyclone tracks at each city and the cyclone tracks at all other grid points throughout North America. By construction, the cyclone tracks at each city are positively correlated with cyclone tracks within $500 \mathrm{~km}$ (see methodology in section 2c). However, the point correlations also reveal upstream and downstream linkages in the cyclone tracks. The correlations suggest the following: 1) cyclone tracks at Atlanta arise largely from the Gulf of Mexico and southern plains, 2) cyclone tracks at New York and Toronto arise from both the Canadian Rockies and the southern plains, and 3) cyclone tracks at St. John's arise from both the Canadian Rockies and the eastern seaboard of the United States. The cyclone tracks at each location are also anticorrelated with tracks to the northwest and southeast.

To better understand the variability in the cyclone tracks at each city, the right column of Fig. 9 shows the regressions of $500-\mathrm{hPa}$ streamfunction anomalies onto standardized time series of cyclone counts at each city. To focus on teleconnection patterns, we use the $500-\mathrm{hPa}$ streamfunction field to approximate the nondivergent, equivalent barotropic component of the tropospheric flow. The cyclone track variability at Atlanta, New York, and Toronto is associated with Rossby wave train patterns similar to those associated with ENSO, PNA, and MJO (Fig. 8). For instance, the streamfunction patterns for Atlanta and New York strongly resemble the Rossby wave train associated with the positive phase of the PNA (Fig. 8, bottom left), with the node over the western United States somewhat biased equatorward in comparison to that of the PNA. Likewise, the 

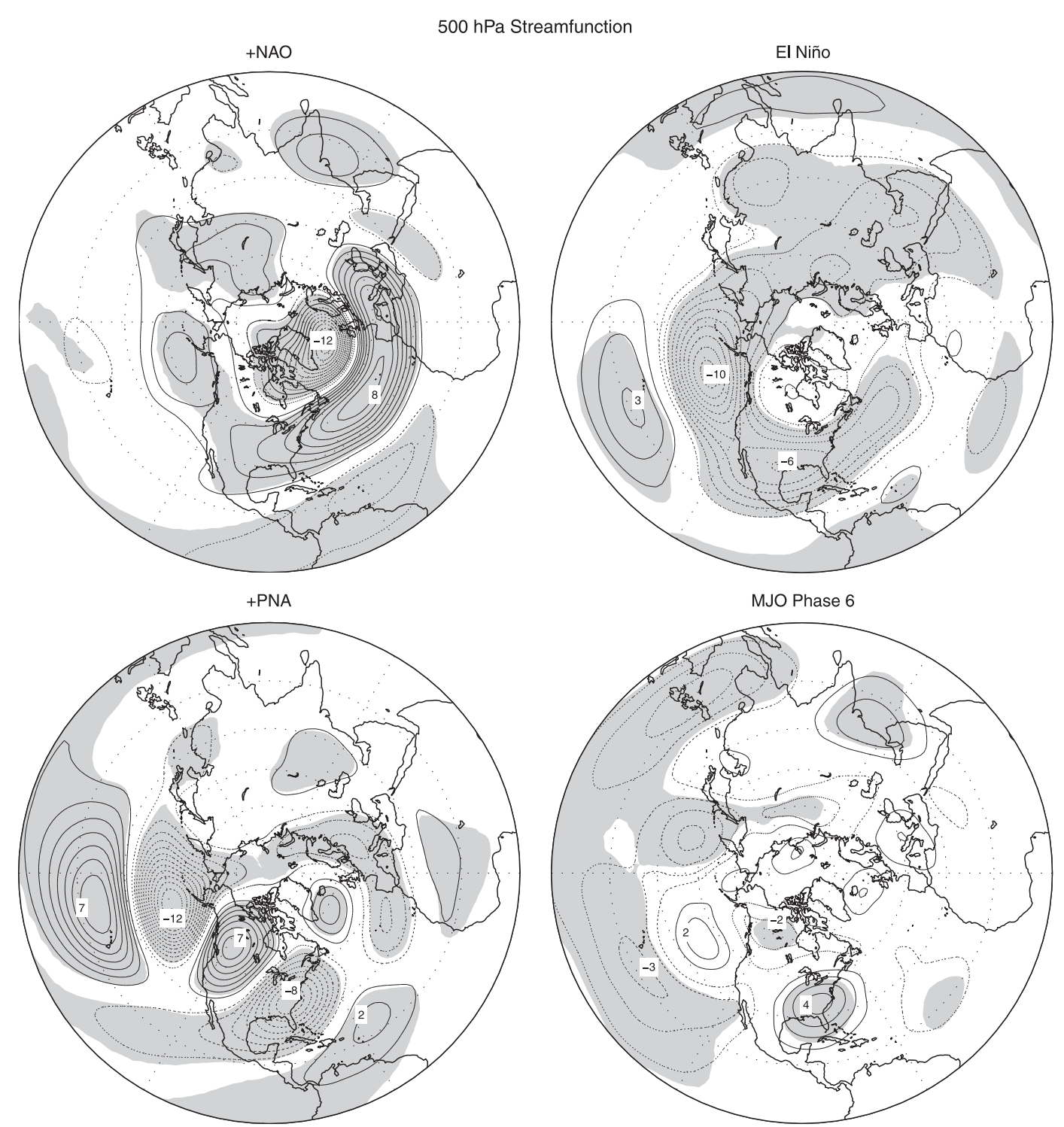

FIG. 8. Composites of 500-hPa streamfunction anomalies during November-March: (top left) positive phase of the NAO, (top right) El Niño, (bottom left) positive phase of the PNA, and (bottom right) phase 6 of the MJO. The contour interval is $1.0 \times 10^{6} \mathrm{~m}^{2} \mathrm{~s}^{-1}$. Regions that are $95 \%$ significant via a Monte Carlo test are denoted by gray shading.

streamfunction pattern for Toronto resembles the Rossby wave train associated with La Niña (opposite polarity to Fig. 8, top right).

In fact, cyclone track variability at most cities in North America is more strongly linked to Rossby wave trains excited over the Pacific sector than to NAO-type variability (i.e., the patterns in Fig. 9 at Atlanta, New York, and Toronto are typical examples over eastern North America). It is only at cities in the far northeastern United States and eastern Canada (e.g., St. John's) that NAO-type variability is a more dominant contributor (Fig. 9, bottom right). NAO-type variability is also strongly linked to variability in high-latitude cyclone tracks, particularly those extending southeastward from the Canadian Arctic across Hudson Bay toward northern Ontario and Quebec, Canada (Fig. 3).

Thus, a key finding of this study is the important role of Pacific sector climate phenomena (i.e., ENSO, PNA, and $\mathrm{MJO}$ ) in the interannual and intraseasonal variability of storm tracks across much of North America. Forecasters are well experienced with the influences of ENSO on North American weather, but the results shown here confirm that other Pacific sector phenomena are linked to similar spatial variability in the North 

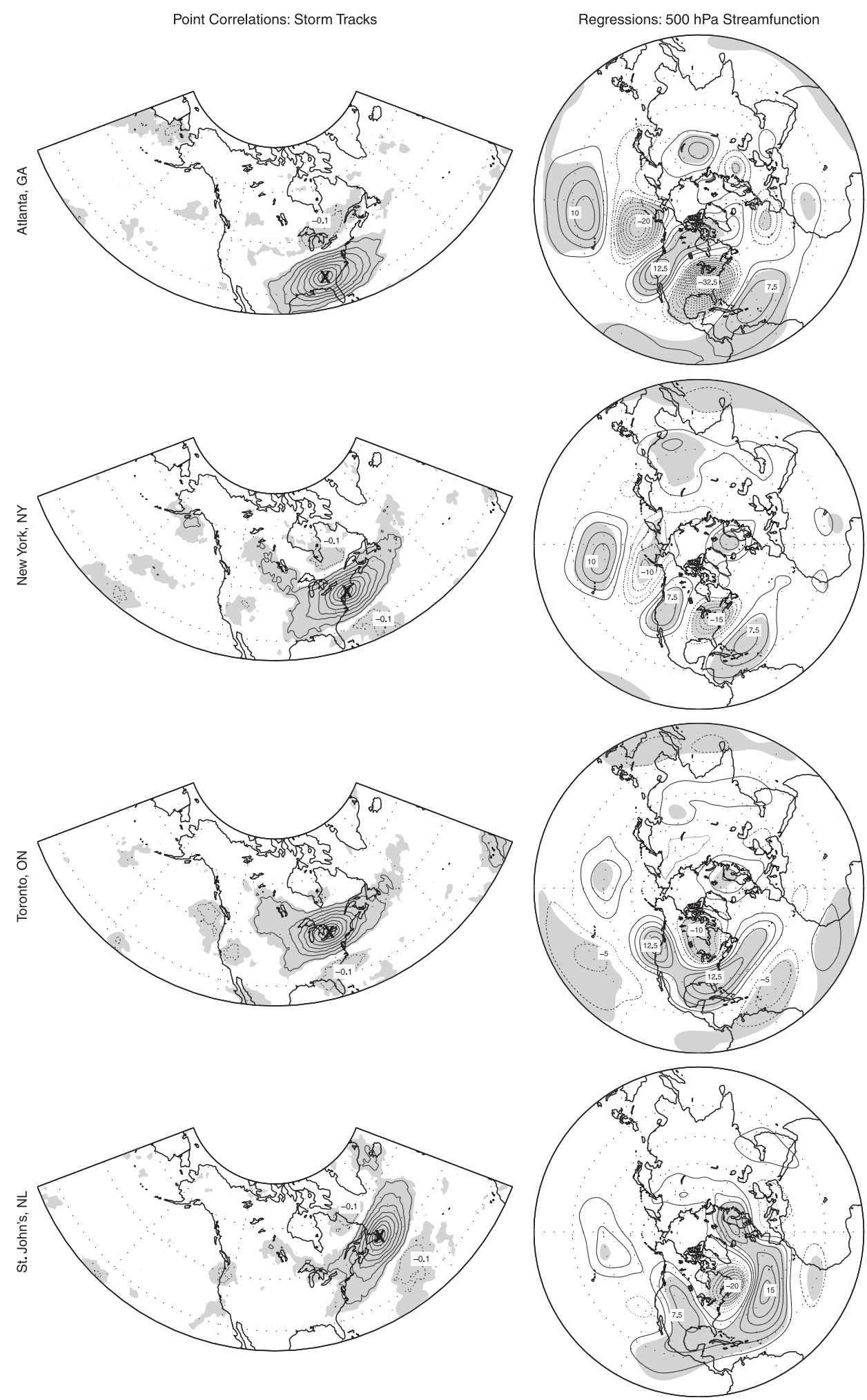

FIG. 9. (left) Point correlations of pentad-mean cyclone track anomalies with the pentad-mean cyclone track anomaly at selected North American cities (marked by " $X$ "). The contour interval is 0.1 . (right) Regressions of pentad-mean 500-hPa streamfunction anomalies onto standardized indices of the number of cyclones at each point shown at (left). The contour interval is $2.5 \times 10^{5} \mathrm{~m}^{2} \mathrm{~s}^{-1}$. Positive contours are solid, negative contours are dashed, and the zero contour is omitted. The shading indicates regions that are $95 \%$ significant. 
American storm tracks (Figs. 4-6). Future work might consider how decadal variability and trends in tropical convection and the wave train pattern over the Pacific Ocean relate to decadal variability and trends in North American storm tracks and weather.

The results of this study document a relationship between high-frequency storm-track variability and lowfrequency tropospheric variability, but we emphasize that the results shown here do not address causality. In the case of the NAO and PNA, there is little distinction between the storm-track variability and the teleconnection patterns themselves, which are driven by high-frequency midlatitude transient eddies. In the case of ENSO and the $\mathrm{MJO}$, the storm-track variability is driven in part by tropical diabatic heating but also reflects internal extratropical dynamics.

North American storm tracks are also affected by local sea surface temperature and sea ice variability on interannual time scales (e.g., Magnusdottir et al. 2004). Additionally, variability in the stratospheric circulation may influence the storm tracks on intraseasonal time scales (e.g., Baldwin and Dunkerton 2001). Hence, to better understand variability and long-term change in the North American storm tracks, one also needs to consider both surface and stratospheric influences. This issue will be addressed in future study.

Acknowledgments. We thank P. E. Roundy and two anonymous reviewers for helpful comments during the preparation of this manuscript. We also thank K. I. Hodges for providing us with his tracking algorithm. This project was supported with funding from the Ouranos Consortium on Regional Climatology and Adaptation to Climate Change, Montreal, Canada.

\section{REFERENCES}

Angel, J. R., and S. Isard, 1998: The frequency and intensity of Great Lake cyclones. J. Climate, 11, 61-71.

Athanasiadis, P. J., J. M. Wallace, and J. J. Wettstein, 2010: Patterns of wintertime jet stream variability and their relation to the storm tracks. J. Atmos. Sci., 67, 1361-1381.

Baldwin, M. P., and T. J. Dunkerton, 2001: Stratospheric harbingers of anomalous weather regimes. Science, 294, 581-584.

Barnes, E. A., and D. L. Hartmann, 2010: Dynamical feedbacks and the persistence of the NAO. J. Atmos. Sci., 67, 851-865.

Barnston, A. G., M. Chelliah, and S. B. Goldenberg, 1997: Documentation of a highly ENSO-related SST region in the equatorial Pacific. Atmos.-Ocean, 35, 367-383.

Becker, E. J., E. H. Berbery, and R. W. Higgins, 2011: Modulation of cold-season U.S. daily precipitation by the Madden-Julian oscillation. J. Climate, 24, 5157-5166.

Bjerknes, J., 1969: Atmospheric teleconnections from the equatorial Pacific. Mon. Wea. Rev., 97, 163-172.

Blackmon, M. L., J. M. Wallace, N.-C. Lau, and S. L. Mullen, 1977: An observational study of the Northern Hemisphere wintertime circulation. J. Atmos. Sci., 34, 1040-1053.
Cassou, C., 2008: Intraseasonal interaction between the MaddenJulian Oscillation and the North Atlantic Oscillation. Nature, 455, 523-527.

Chang, E. K. M., S. Lee, and K. L. Swanson, 2002: Storm track dynamics. J. Climate, 15, 2163-2183.

Charney, J. G., 1947: The dynamics of long waves in a baroclinic westerly current. J. Meteor., 4, 135-162.

Dee, D. P., and Coauthors, 2011: The ERA-Interim reanalysis: Configuration and performance of the data assimilation system. Quart. J. Roy. Meteor. Soc., 137, 553-597.

Deng, Y., and T. Jiang, 2011: Intraseasonal modulation of the North Pacific storm track by tropical convection in boreal winter. J. Climate, 24, 1122-1137.

Eady, E. T., 1949: Long waves and cyclone waves. Tellus, 1, 33-52.

Eichler, T., and W. Higgins, 2006: Climatology and ENSO-related variability of North American extratropical cyclone activity. J. Climate, 19, 2076-2093.

Feldstein, S. B., 2000: The timescale, power spectra, and climate noise properties of teleconnection patterns. J. Climate, 13, 4430-4440.

Gerber, E. P., and G. K. Vallis, 2009: On the zonal structure of the North Atlantic Oscillation and annular modes. J. Atmos. Sci., 66, 332-352.

Held, I. M., S. W. Lyons, and S. Nigam, 1989: Transients and the extratropical response to El Niño. J. Atmos. Sci., 46, 163-174.

Hirsch, M., A. DeGaetano, and S. Colucci, 2001: An East Coast winter storm climatology. J. Climate, 14, 882-899.

Hodges, K. I., 1994: A general method for tracking analysis and its application to meteorological data. Mon. Wea. Rev., 122, 2573-2586.

- 1995: Feature tracking on the unit sphere. Mon. Wea. Rev., 123, 3458-3465. , 1999: Adaptive constraints for feature tracking. Mon. Wea. Rev., 127, 1362-1373.

- 2008: Confidence intervals and significance tests for spherical data derived from feature tracking. Mon. Wea. Rev., 136, $1758-1777$.

Horel, J. D., and J. M. Wallace, 1981: Planetary-scale atmospheric phenomena associated with the Southern Oscillation. Mon. Wea. Rev., 109, 813-829.

Hoskins, B. J., and D. J. Karoly, 1981: The steady linear response of a spherical atmosphere to thermal and orographic forcing. J. Atmos. Sci., 38, 1179-1196.

_ , and K. I. Hodges, 2002: New perspectives on the Northern Hemisphere winter storm tracks. J. Atmos. Sci., 59, 10411061.

— M. E. McIntyre, and A. W. Robertson, 1985: On the use and significance of isentropic potential vorticity maps. Quart. J. Roy. Meteor. Soc., 111, 877-946.

Hurrell, J. W., 1995: Decadal trends in the North Atlantic Oscillation: Regional temperatures and precipitation. Science, 269, 676-679.

_ , Y. Kushnir, G. Ottersen, and M. Visbeck, 2003: An overview of the North Atlantic Oscillation. North Atlantic Oscillation: Climatic Significance and Environmental Impact, Geophys. Monogr., Vol. 134, Amer. Geophys. Union, 1-35.

Klein, W. H., 1957: Principal tracks and mean frequencies of cyclones and anticyclones in the Northern Hemisphere. U.S. Weather Bureau Research Paper 40, U.S. Weather Bureau, Washington, DC, 60 pp.

Lareau, N. P., and J. D. Horel, 2012: The climatology of synopticscale ascent over western North America: A perspective on storm tracks. Mon. Wea. Rev., 140, 1761-1778. 
Lau, N.-C., 1988: Variability of the observed midlatitude storm tracks in relation to low-frequency changes in the circulation pattern. J. Atmos. Sci., 45, 2718-2743.

Leathers, D. J., B. Yarnal, and M. A. Palecki, 1991: The Pacific/ North American teleconnection pattern and United States climate. Part I: Regional temperature and precipitation associations. J. Climate, 4, 517-528.

L'Heureux, M. L., and R. W. Higgins, 2008: Boreal winter links between the Madden-Julian oscillation and the Arctic Oscillation. J. Climate, 21, 3040-3050.

Lin, H., G. Brunet, and J. Derome, 2009: An observed connection between the North Atlantic Oscillation and the MaddenJulian Oscillation. J. Climate, 22, 364-380.

— - _ , and R. Mo, 2010: Impact of the Madden-Julian oscillation on wintertime precipitation in Canada. Mon. Wea. Rev., 138, 3822-3839.

Lorenz, D. J., and D. L. Hartmann, 2003: Eddy-zonal flow feedback in the Northern Hemisphere winter. J. Climate, 16, 1212-1227.

Madden, R. A., and P. R. Julian, 1994: Observations of the 4050-day tropical oscillation-A review. Mon. Wea. Rev., 122, 814-837.

Magnusdottir, G., C. Deser, and R. Saravanan, 2004: The effects of North Atlantic SST and sea ice anomalies on the winter circulation in CCM3. Part I: Main features and storm track characteristics of the response. J. Climate, 17, 857-876.

Murray, R. J., and I. Simmonds, 1991: A numerical scheme for tracking cyclone centres from digital data. Part I: Development and operation of the scheme. Aust. Meteor. Mag., 39, $155-166$.

Nakamura, H., M. Tanaka, and J. M. Wallace, 1987: Horizontal structure and energetics of Northern Hemisphere wintertime teleconnection patterns. J. Atmos. Sci., 44, 3377-3391.

Noel, J., and D. Changnon, 1998: A pilot study examining U.S. winter cyclone frequency patterns associated with three ENSO parameters. J. Climate, 11, 2152-2159.

Pfahl, S., and H. Wernli, 2012: Quantifying the relevance of cyclones for precipitation extremes. J. Climate, 25, 6770-6780.

Reynolds, R. W., N. A. Rayner, T. M. Smith, D. C. Stokes, and W. Wang, 2002: An improved in situ and satellite SST analysis for climate. J. Climate, 15, 1609-1625.

Riddle, E. E., M. B. Stoner, N. C. Johnson, M. L. L'Heureux, D. C. Collins, and S. B. Feldstein, 2013: The impact of the MJO on clusters of wintertime circulation anomalies over the North American region. Climate Dyn., 40, 1749-1766, doi:10.1007/ s00382-012-1493-y.

Rogers, J. C., 1990: Patterns of low-frequency monthly sea level pressure variability (1899-1986) and associated wave cyclone frequencies. J. Climate, 3, 1364-1379.

Sardeshmukh, P. D., and B. J. Hoskins, 1988: The generation of global rotational flow by steady idealized tropical divergence. J. Atmos. Sci., 45, 1228-1251.
Serreze, M. C., F. Carse, R. G. Barry, and J. C. Rogers, 1997: Icelandic low cyclone activity: Climatological features, linkages with the NAO, and relationships with recent changes in the Northern Hemisphere circulation. J. Climate, 10, 453-464.

Sinclair, M. R., 1997: Objective identification of cyclones and their circulation intensity and climatology. Wea. Forecasting, 12, 595-612.

Son, S.-W., M. Ting, and L. M. Polvani, 2009: The effect of topography on storm track intensity in a relatively simple general circulation model. J. Atmos. Sci., 66, 393-411.

Straub, K. H., 2013: MJO initiation in the Realtime Multivariate MJO index. J. Climate, 26, 1130-1151.

Straus, D. M., and J. Shukla, 1997: Variations of midlatitude transient dynamics associated with ENSO. J. Atmos. Sci., 54, $777-790$

Thompson, D. W. J., S. Lee, and M. P. Baldwin, 2003: Atmospheric processes governing the Northern Hemisphere Annular Mode/ North Atlantic Oscillation. North Atlantic Oscillation: Climatic Significance and Environmental Impact, Geophys. Monogr., Vol. 134, Amer. Geophys. Union, 81-112.

Trenberth, K. E., 1991: Storm tracks in the Southern Hemisphere. J. Atmos. Sci., 48, 2159-2178.

_ 1997: The definition of El Niño. Bull. Amer. Meteor. Soc., 78, 2771-2777.

— , and J. W. Hurrell, 1994: Decadal atmosphere-ocean variations in the Pacific. Climate Dyn., 9, 303-319.

Ulbrich, U., G. C. Leckebusch, and J. G. Pinto, 2009: Extra-tropical cyclones in the present and future climate: A review. Theor. Appl. Climatol., 96, 117-131.

Wallace, J. M., and D. S. Gutzler, 1981: Teleconnections in the geopotential height field during the Northern Hemisphere winter. Mon. Wea. Rev., 109, 784-812.

_ G. H. Lim, and M. L. Blackmon, 1988: Relationship between cyclone tracks, anticyclone tracks, and baroclinic waveguides. J. Atmos. Sci., 45, 439-462.

Wang, X. L., H. Wan, and V. R. Swail, 2006: Observed changes in cyclone activity in Canada and their relationships to major circulation regimes. J. Climate, 19, 896-915.

Wheeler, M. C., and H. H. Hendon, 2004: An all-season real-time multivariate MJO index: Development of an index for monitoring and prediction. Mon. Wea. Rev., 132, 1917-1932.

Zhang, Y., and I. M. Held, 1999: A linear stochastic model of a GCM's midlatitude storm tracks. J. Atmos. Sci., 56, 3416-3435.

Zhou, S., M. L'Heureux, S. Weaver, and A. Kumar, 2012: A composite study of the MJO influence on the surface air temperature and precipitation over the continental United States. Climate Dyn., 38, 1459-1471.

Zishka, K. M., and P. J. Smith, 1980: The climatology of cyclones and anticyclones over North America and surrounding ocean environs for January and July, 1950-1977. Mon. Wea. Rev., 108, 387-401. 